•研究报告・

\title{
牛耳朵和马坝报春苣苔同域种群 授粉后的生殖隔离
}

\author{
张小龙 ${ }^{1}$ 杨丽华 ${ }^{1,2}$ 康 明 $^{1^{*}}$ \\ 1 (中国科学院华南植物园，中国科学院植物资源保护与可持续利用重点实验室，广州 510650) \\ 2 (中国科学院大学, 北京 100049)
}

\begin{abstract}
摘要: 生殖隔离是物种形成的关键, 也是物种保持完整性和独立性的基础。报春亘苔属(Primulina)是我国苦苣苔 科中最大的属, 具有极为丰富的物种多样性。大部分报春芭苔属植物为喀斯特地区特有植物, 近缘种的同域分布 也相当普遍。为更好地理解该属植物的物种多样性形成及维持机制, 我们选取了牛耳朵( P. eburnea) 和马坝报春芭 苔(P. mabaensis)的同域种群, 分析了授粉后的多种隔离机制强度, 主要包括花粉竞争、坐果率、种子重量、种子 萌发率、花粉活力。结果显示, 牛耳朵和马坝报春苣苔的授粉后总隔离强度都较弱 $(0.09$ vs. 0.13$)$, 其中花粉竞争及 种子萌发率的隔离强度为负值, 对物种间基因流发生起促进作用; 而坐果率、种子重量以及花粉活力的隔离强度 均为正值, 表现为对种间基因流起阻止作用。牛耳朵和马坝报春菅苔较弱的授粉后隔离机制不足以完全阻止物种 间杂交、保持物种独立性，但野外较少存在自然杂交个体暗示着两者可能存在较强的授粉前隔离机制。
\end{abstract}

关键词：喀斯特植物；报春苣苔属；同域种群；生殖隔离；杂交；花粉竞争

\section{Post-pollination reproductive isolation of sympatric populations of Pri- mulina eburnea and P. mabaensis (Gesneriaceae)}

\author{
Xiaolong Zhang ${ }^{1}$, Lihua Yang ${ }^{1,2}$, Ming Kang ${ }^{1 *}$ \\ 1 Key Laboratory of Plant Resources Conservation and Sustainable Utilization, South China Botanical Garden, Chinese \\ Academy of Sciences, Guangzhou 510650 \\ 2 University of Chinese Academy of Sciences, Beijing 100049
}

\begin{abstract}
Reproductive isolation is essential for sympatric populations of closely related species to maintain species integrity and to prevent genetic introgression caused by hybridization. Primulina is the largest genus of Gesneriaceae in China, with a high degree of species diversity and endemism. Most species of the genus are karst habitat specialists (i.e. calciphiles), and many closely related species show a sympatric distribution in karst landscapes. To better understand the mechanism of sympatry in Primulina, post-pollination reproductive isolation, including pollen competition, fruit set, seed mass, seed germination, and pollen viability, was investigated in two closely related species, $P$. eburnea and P. mabaensis. Results indicated that the total post-pollination isolation strength for P. eburnea and P. mabaensis was 0.09 and 0.13 , respectively, which were not strong enough to prevent hybridization completely. The strength of reproductive isolation from pollen competition and seed germination of P. eburnea and P. mabaensis was negative, suggesting facilitation for gene flow between species; while the strength of the fruit set, seed mass, and pollen viability showed a weak role in preventing interspecies hybridization. However, the two species are able to maintain their integrity well, as rare hybrid individuals are found in nature, suggesting that the existence of pre-pollination isolation mechanisms may play a more important role in maintaining species boundaries in these two species.

Key words: karst plant; Primulina; sympatric populations; reproductive isolation; hybridization; pollen competition
\end{abstract}

收稿日期: 2017-02-01; 接受日期: 2017-04-06

基金项目：国家自然科学基金-广东省联合基金重点项目(U1501211)

*通讯作者 Author for correspondence. E-mail: mingkang@scib.ac.cn 
生殖隔离是物种形成的关键，也是物种保持完 整性和独立性的基础(Coyne \& Orr, 2004)。根据发生 时间段的不同，生殖隔离可划分为合子前隔离及合 子后隔离(Kay, 2006), 在植物中也可以划分为授粉 前隔离和授粉后隔离(Baack et al, 2015)。授粉前隔 离包括生态地理隔离、花期隔离、传粉者隔离等; 授 粉后隔离指发生在花粉落至在柱头后的阶段, 主要 包括花粉竞争、杂交种子形成、杂种不育、杂种衰 败等(Baack et al, 2015)。通常会由多种不同的授粉 前及授粉后隔离机制共同作用来阻止种群间或物 种间的基因流发生。详细评价各种隔离机制的相对 作用是理解物种形成及物种边界维持的关键 (Martin \& Willis, 2007)。当物种间的生殖隔离强度 不足以完全阻断基因流的发生时, 两个物种就可能 发生杂交融合, 甚至导致亲本物种的灭绝, 尤其是 狭域特有种的灭绝风险更高(Rhymer \& Simberloff, 1996; Wolf et al, 2001)。

报春苣苔属(Primulina) 是苦苣苔科的一个大属, 有超过 150 个种, 主要分布在我国南部、西南部及越 南北部的石灰岩地区(Möller et al, 2016)。该类群绝 大多数物种为极其狭域的地方特有种, 且有较强的 生长基质专性, 只存在少数的广布种, 如牛耳朵 $(P$. eburnea)、蚂蝗七(P. fimbrisepala) 等。异域物种形成 被认为可能是这个类群的主要物种形成机制, 如喀 斯特地貌导致的地理隔离(Gao et al, 2015)。这些异 域分化的物种在发生二次相遇时(如广布种在它的 分布区内经常和一些狭域种相遇), 需要快速地再 次建立较强的生殖隔离才能阻止物种间的杂交融 合，保持自身的独立性和完整性。牛耳朵是华南石 灰岩地区常见的广布种(Wang et al, 1998), 而马坝 报春菅苔(P. mabaensis) 是近年新发表的一个狭域特 有种(Chung et al, 2013), 目前只有一个分布点。马 坝报春苣苔的生长地同时混合生长着牛耳朵, 两者 花期存在部分重叠, 且具有较近的亲缘关系(Kang et al，2014), 但我们的野外观察发现两个物种可以 很好地保持各自的独立性和完整性, 很少有杂交过 渡个体。牛耳朵和马坝报春苣苔是通过哪些隔离机 制来维持各自的物种边界? 其各种隔离机制的相 对作用强度如何? 本文详细研究了牛耳朵和马坝 报春苣苔的授粉后生殖隔离机制及其相对贡献, 研 究结果对于理解近缘物种同域分布的维持机制具 有重要意义。

\section{1 材料与方法}

\section{1 研究材料}

牛耳朵具有一对大而显著的苞片, 花较大(长 3-4 cm)而艳丽(图1E), 花丝在中部膝状弯曲(图1D), 花药整个腹面联合(图1D), 花期4-5月(Wang et al, 1998)。马坝报春菅苔苞片不显著, 花较小(长2.5$3 \mathrm{~cm}$ )而白色(图1G), 花丝直(图1C), 花药分离(图 1C)，花期4-6月(Chung et al, 2013)。

在马坝人遗址景区内，两个物种混合生长(图 1A), 并且存在部分花期重叠, 但在野外两个物种 可以很好地保持自身的完整性，偶尔见到杂交个体 (图1B，F)。2012年，我们对此分布点的两个物种每 隔 $1 \mathrm{~m}$ 进行少量引种, 并用 $12 \mathrm{~cm}$ 花盆栽植于华南植 物园温室内，2013-2014年开花后进行下列生殖隔 离检验实验。

\section{2 研究方法}

\subsection{1 花粉大小及花柱长度}

每个物种随机取 3 株, 每株 1 朵成熟花, 将花粉 挤出在玻片上混匀, 在显微镜下拍照。每个物种选 取30粒以上发育正常的花粉粒, 用ImageJ软件测量 其长、宽、面积。随机选取 10 朵成熟花朵, 用数码 卡尺测量两个物种的花柱长度。

\subsection{2 花粉管生长}

分别对两个物种做以下人工授粉处理(每个处 理10朵以上花):(1)种内自交: 开花前套袋，开花后 自花授粉，再套袋; (2)种间杂交：开花前套袋，开 花后分别对两个物种进行杂交 $($ 牛耳朵 $\hat{\delta} \times$ 马坝报春 苣苔早, 牛耳朵早 $\times$ 马坝报春菅苔 $\hat{o})$, 再套袋。授粉 $2 \mathrm{~h}$ 后将雌荵取下立即置于新鲜的卡诺氏固定液(3 乙醇：1乙酸)中固定。 $24 \mathrm{~h}$ 后, 用蒸馏水漂洗 $3 \mathrm{~min}$, 重复2次, 用卡尺测量雌荵长度, 再将其浸泡在 $4 \mathrm{M}$ 的氢氧化钠溶液中软化 $24 \mathrm{~h}$ 后, 用蒸馏水漂洗 2 次, 每次 $3 \mathrm{~min}$, 置于洁净玻片上, 滴加 2 滴 $0.1 \%$ 的水溶 性苯胺蓝染色液, 染色5 min, 盖上盖玻片, 轻压使 柱头压扁平铺。在苂光显微镜DAPI通道410 nm波长 紫外光条件下观察花粉管生长状态, 并测量花粉管 长度。

\subsection{3 花粉竞争}

开花前套袋并去雄，开花后将两个物种的花粉 按 $1: 1$ 等重量混合均匀, 再分别授在两个物种的柱 头上，套袋至花谢。待果实成熟并风干后，分别将 


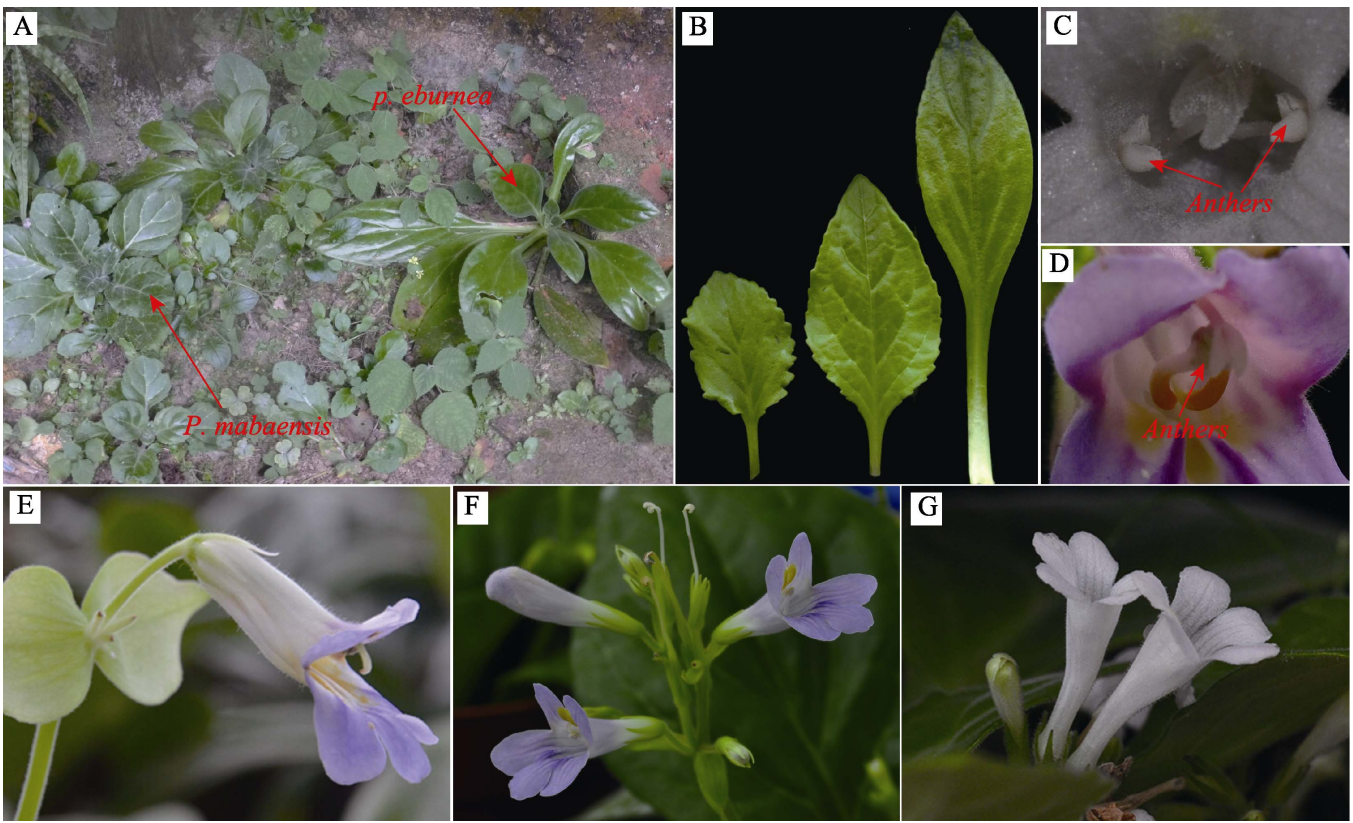

图1 牛耳朵、马坝报春苣苔及其杂交 $F_{1}$ 代植株、花和叶。(A)牛耳朵和马坝报春苣苔野外植株; (B)牛耳朵(右)、杂交 $\mathrm{F}_{1}$ 代 $($ 中 $)$ 和马坝报春芦苔(左)的叶; $(\mathrm{C})$ 马坝报春苣苔花药; $(\mathrm{D})$ 牛耳朵花药; $(\mathrm{E})$ 牛耳朵花; $(\mathrm{F})$ 杂交 $F_{1}$ 代花; $(\mathrm{G})$ 马坝报春苣苔花。

Fig. 1 Plant, flower and leaf of Primulina eburnea, P. mabaensis and their hybrid. (A) Plants of P. eburnea and P. mabaensis in field; (B) Leaves of $P$. eburnea (right), hybrid (middle) and P. mabaensis (left); (C) Flower of P. mabaensis showing anthers; (D) Flower of P. eburnea showing anthers; (E) Flowers of P. eburnea; (F) Flowers of hybrid; (G) Flowers of P. mabaensis.

每个果实的种子散播在放置有培养土的培养血中, 盖上培养具, 放在 $25^{\circ} \mathrm{C}$ 的培养箱内, 注意保湿。待 长出小苗后随机选取30株, 采用改良的CTAB法分 别提取DNA，再用表1中的3对物种特异性SSR引物 进行PCR扩增, 对扩增样品进行毛细管电泳检测扩 增片段长度。

先期实验笁选出3对物种特异性SSR标记(引物 信息见表1)，即这些标记在亲本上为具有种间多态 性的纯合位点(Ai et al, 2015)。因此, 若样本在相应 的标记上为杂合状态, 则表明该个体在混合授粉后 接受了异源花粉。反之, 则表明该个体在混合授粉 后接受了同源花粉。

\subsection{4 坐果率及种子重量}

花期内对两个物种分别进行以下人工授粉处
理: (1)种内自交 $(n=20)$ : 开花前套袋, 开花后自花 授粉，再套袋至花谢; (2)种间杂交 $(n=30)$ : 开花前 套袋并去雄, 开花后分别对两个物种进行相互杂交 (牛耳朵 $\hat{0} \times$ 马坝报春菅苔우, 牛耳朵 苣苔全), 套袋至花谢。果实成熟后分别统计各个处 理的坐果率。果实风干后每组随机选取 10 个发育正 常的果实, 用电子天平称量每个果实的种子总重量。

\subsection{5 花粉活力}

分别随机选取牛耳朵和马坝报春苣苔亲本及 上述种间杂交 $F_{1}$ 代 3 株, 每株取 1 朵花, 将花粉挤出 并在玻片上涂匀, 滴加 1 滴TTC染色液, 轻轻盖上盖 玻片后, 置于铺有潮湿滤纸的培养皿内, $35^{\circ} \mathrm{C}$ 放置 $30 \mathrm{~min}$ 以上, 在显微镜下 $(4 \times 20$ 倍 $)$ 分别统计视野内 淡红色或者红色的花粉占总花粉数的比例, 共统计

表1 SSR引物信息及扩增长度多态性

Table 1 SSR primer information and amplified fragment length polymorphism

\begin{tabular}{|c|c|c|c|c|}
\hline \multirow[t]{2}{*}{$\begin{array}{l}\text { 引物名称 } \\
\text { Primer }\end{array}$} & \multirow[t]{2}{*}{$\begin{array}{l}\text { 正向引物 } \\
\text { Forward primer }\end{array}$} & \multirow[t]{2}{*}{$\begin{array}{l}\text { 反向引物 } \\
\text { Reverse primer }\end{array}$} & \multicolumn{2}{|c|}{$\begin{array}{l}\text { 扩增片段长度多态性 Amplified fragment length polymor- } \\
\text { phism (bp) }\end{array}$} \\
\hline & & & 牛耳朵 Primulina eburnea & 马坝报春菅苔 P. mabaensis \\
\hline 325 & AACGGAGAACACCCCATTTA & TCGCCTTATGAAGGTTTTGG & 249 & 246 \\
\hline 415 & AACCCATCGTTTCACTCCAC & CTCGGAATCAACTCCTAGCG & 289 & 299 \\
\hline 1143 & CGGAGTCAGCTTTGCACATA & СТСТСТССТАCАCACGAGCG & 222 & 219 \\
\hline
\end{tabular}


10 个视野, 取平均值即为花粉活力(Dafni, 1992)。

\subsection{6 种子萌发率}

各取 10 个上述 4 种人工授粉处理的发育正常的 果实, 每个果实取 100 粒种子散播在放置有培养土 的培养血中, 盖上培养典, 放在 $25^{\circ} \mathrm{C}$ 的培养箱内, 注意保湿, 60 天后统计萌发率。10 个果实的平均萌 发率代表该组处理的萌发率。

\subsection{7 生殖隔离强度的计算}

采取Sobel和Chen (2014)提出的计算方法来分 析授粉后每个特定时期的生殖隔离强度。隔离机制 强度基本算法为: $\mathrm{RI}=1-2 \times[\mathrm{H} /(\mathrm{H}+\mathrm{C})]$ 。 $\mathrm{RI}$ 为隔离机 制的强度, $\mathrm{H}$ 为异源授粉后代的适合度, $\mathrm{C}$ 为同源授 粉后代的适合度, $\mathrm{H} /(\mathrm{C}+\mathrm{H})$ 为基因交流发生的可能 性。根据此方法, 生殖隔离强度(RI)值在 -1.0 到 1.0 之间, 如, 当 $1: 1$ 混合花粉授粉后, 若种子全部为同 源花粉所得到, 则基因流为 0 , 隔离强度为 1 ; 若种 子全部为异源花粉所得到, 则基因流为 1 , 隔离强 度为 -1 ; 若两种花粉的授粉能力相同, 则基因流为 0.5 , 隔离强度为 0 。具体每个时期的隔离强度的计 算及变量的详细情况如表 2 。授粉后总的隔离强度为 各个特定时期隔离绝对贡献值的总和。

\section{2 结果}

\section{1 花粉大小及花柱长度}

牛耳朵花粉粒长度平均为 $28.14 \pm 0.61 \mu \mathrm{m}$, 宽 度平均为 $14.99 \pm 0.49 \mu \mathrm{m}$, 面积平均为 $334.02 \pm$ $12.69 \mu \mathrm{m}^{2}$; 马坝报春苣苔花粉粒长度平均为 $32.79 \pm$ $0.92 \mu \mathrm{m}$, 宽度平均为 $17.58 \pm 0.72 \mu \mathrm{m}$, 面积平均为
$461.82 \pm 22.17 \mu \mathrm{m}^{2}$ 。牛耳朵的花粉粒较马坝报春苣 苔花粉粒稍小, 其长度、宽度和面积比值分别为 $1: 1.17 、 1: 1.17 、 1: 1.38$ 。牛耳朵花柱长度平均为 $9.87 \pm$ $0.85 \mathrm{~mm}$ ，马坝报春苣苔花柱长度平均为 $19.52 \pm$ $1.01 \mathrm{~mm}$, 二者花柱长度比值为 $1: 1.98$ 。

\section{2 花粉管生长}

牛耳朵种内自交花粉管长度为 $925.78 \pm 56.17 \mu \mathrm{m}$, 种间杂交 $($ 牛耳朵 $9 \times$ 马坝报春菅苔全)的花粉管长 度为 $722.53 \pm 153.87 \mu \mathrm{m}$, 种内自交比种间杂交的花 粉管长 $28.13 \%$ 。马坝报春苣苔种内自交花粉管长度 为771.66 $\pm 338.17 \mu \mathrm{m}$, 种间杂交(马坝报春芭苔早 $\times$ 牛耳朵全)的花粉管长度为 $387.92 \pm 102.38 \mu \mathrm{m}$, 种内自交比种间杂交的花粉管长 $128.18 \%$ 。无论是 牛耳朵还是马坝报春菅苔, 自交后代的花粉管生长 均比杂交后代快。

\section{3 花粉竞争}

$1: 1$ 混合花粉授粉后, 通过3对SSR标记检测后 代花粉来源的结果显示马坝报春菅苔的花粉对牛 耳朵进行异源授粉的比率为 $66.05 \%$; 牛耳朵花粉对 马坝报春苣苔的异源授粉率为 $51.29 \%$ 。异源花粉均 表现出一定的优势。

\section{4 坐果率}

牛耳朵种内自交坐果率为 $100 \%$, 种间杂交(牛 耳朵早 $\times$ 马坝报春苣苔合)的坐果率为 $88.56 \%$; 马坝 报春菅苔种内自交坐果率为 $87.96 \%$, 种间杂交(马 坝报春苣苔早 $\times$ 牛耳朵令)的坐果率为 $87.43 \%$ 。

\section{5 种子重量}

牛耳朵种内自交每个果实内所有种子的平均

表2 各种生殖隔离机制强度的计算及其变量情况

Table 2 Equations used to quantify components of reproductive isolation. Details of how the variables were constructed are given in the text.

\begin{tabular}{ll}
\hline 隔离机制 Isolation barriers & 计算方程 Equation for calculating reproductive isolation (RI) \\
\hline 花粉竞争 & $1-2 \times[$ 异源花粉授粉率/(异源花粉授粉率+同源花粉授粉率) $]$ \\
Pollen competition & $1-2 \times[$ interspecific pollination ratio/(interspecific pollination rate + intraspecific pollination rate) $]$ \\
坐果率 & $1-2 \times[$ 杂交坐果率/(杂交坐果率+自交坐果率) $]$ \\
Fruit set & $1-2 \times[$ interspecific fruit set/(interspecific fruit set + selfing fruit set) $]$ \\
种子重量 & $1-2 \times[$ 杂交种子重量/(杂交种子重量 + 自交种子重量) $]$ \\
Seed mass & $1-2 \times[$ interspecific seed mass of per fruit/(interspecific seed mass of per fruit + selfing seed mass of per fruit) $]$ \\
种子萌发率 & $1-2 \times[$ 杂交种子萌发率/(杂交种子萌发率+自交种子萌发率) $]$ \\
Seed germination rate & $1-2 \times[$ interspecific seed germination/(interspecific seed germination + selfing seed germination) $]$ \\
花粉活力 & $1-2 \times\left[\right.$ 杂交 $F_{1}$ 代花粉活力/(杂交 $F_{1}$ 代花粉活力+亲本花粉活力)] \\
Pollen viability & $1-2 \times\left[\right.$ interspecific $\mathrm{F}_{1}$ pollen viability/(interspecific $\mathrm{F}_{1}$ pollen viability + parent pollen viability)] \\
\hline
\end{tabular}


重量为 $160.41 \pm 90.00 \mathrm{mg}$, 种间杂交 $($ 牛耳朵 $9 \times$ 马 坝报春菅苔令)每个果实内所有种子的平均重量为 $116.98 \pm 68.72 \mathrm{mg}$ 。马坝报春菅苔种内自交每个果 实内所有种子的平均重量为 $29.95 \pm 8.37 \mathrm{mg}$, 种间 杂交 (马坝报春菅苔早 $\times$ 牛耳朵全) 每个果实内所有 种子的平均重量为 $28.90 \pm 8.39 \mathrm{mg}$ 。

\section{6 花粉活力}

亲本中, 牛耳朵花粉活力为 $95.58 \%$, 马坝报春 菅苔的花粉活力为 $94.32 \%$ 。杂交 $F_{1}$ 代的花粉活力显 著低于亲本的花粉活力, 牛耳朵早 $\times$ 马坝报春苣苔 令的 $\mathrm{F}_{1}$ 代花粉活力为 $55.62 \%$, 马坝报春亘苔早 $\times$ 牛耳 朵令的 $\mathrm{F}_{1}$ 代花粉活力为 $47.18 \%$ 。杂交后代花粉活力 明显低于自交后代花粉活力。

\section{7 种子萌发率}

牛耳朵种内自交 $\mathrm{F}_{1}$ 代萌发率平均为 $57.33 \pm$ $27.74 \%$, 种间杂交 $\left(\right.$ 牛耳朵 $9 \times$ 马坝报春苣苔令) $\mathrm{F}_{1}$ 代萌发率为 $62.21 \pm 9.52 \%$ 。马坝报春菅苔种内自 交 $\mathrm{F}_{1}$ 代萌发率平均为 $26.14 \pm 22.42 \%$, 种间杂交 (马 报报春苣苔早 $\times$ 牛耳朵全) $\mathrm{F}_{1}$ 代萌发率为 $39.15 \pm$ $22.31 \%$ 。

\section{8 生殖隔离机制强度}

花粉竞争和种子萌发率的隔离强度为负值, 表 现为对种间杂交起促进作用; 坐果率、种子重量及 花粉活力的隔离强度为正值, 表现为阻止种间杂 交。其中, 花粉活力的隔离强度最大。各种隔离机 制的隔离强度详见表 3 。整合各个生殖隔离指标, 牛 耳朵和马坝报春苣苔的授粉后隔离总强度分别为 0.09 和 0.13 。

表3 牛耳朵和马坝报春苣苔授粉后各生殖隔离机制的强度 Table 3 The strength of post-pollination reproductive isolations between Primulina eburnea and P. mabaensis.

\begin{tabular}{lll}
\hline 隔离机制 & 牛耳杂 & 马坝报春草苔 \\
Isolation barriers & P. eburnea & P. mabaensis \\
\hline 花粉竞争 Pollen competition & -0.321 & -0.026 \\
坐果率 Fruit set & 0.058 & 0.003 \\
种子重量 Seed mass & 0.157 & 0.019 \\
种子萌发率 Seed germination rate & -0.068 & -0.199 \\
花粉活力 Pollen viability & 0.264 & 0.333 \\
授粉后隔离总强度 RI & 0.090 & 0.130 \\
\hline
\end{tabular}

\section{3 讨论}

我们的研究揭示了牛耳朵和马坝报春菅苔同 域种群授粉后各种隔离机制的强度, 结果表明两者
间的授粉后总生殖隔离强度较弱 (分别为 0.09 和 0.13), 不足以完全阻止物种间杂交、保持物种独立 性。很早就有研究认识到同种花粉及花粉管比异种 花粉及花粉管具有更快萌发及生长的优势(Snow \& Spira，1996), 即花粉竞争, 这种机制可能代表一种 有效的生殖隔离机制(Klips，1999; Husband et al, 2002)。花粉 1:1混合授粉产生的种子父本来源显示 两者异源授粉率都要稍微高于同源授粉率(异源授 粉率: 牛耳朵 $(66.05 \%)$ vs. 马坝报春苣苔 $(51.29 \%)$ ), 即花粉竞争表现为对物种间基因流发生起促进作 用(花粉竞争隔离强度: 牛耳朵 $(-0.321)$ vs. 马坝报 春苣苔(-0.026))。不过, 我们应注意到牛耳朵花粉 比马坝报春苣苔花粉略小, 花粉等量混合时, 实际 上牛耳朵的花粉数目要比马坝报春苣苔多, 可能会 对结果造成一定的偏差。种子萌发率的隔离强度也 为负值 (牛耳朵 $(-0.068)$ vs. 马坝报春菅苔 $(-0.199))$, 表明杂交后代具有竞争优势。坐果率、种子重量以 及花粉活力等 3 个指标的隔离强度均为正值, 体现 出对种间基因流的阻止作用, 但这种隔离比较弱, 只有花粉活力的隔离强度稍高, 牛耳朵和马坝报春 苣苔分别为 0.264 和 0.333 。我们的结果也和日常园 艺应用经验相一致, 在日常的园艺杂交中发现报春 苣苔属中大多数物种间可以杂交并产生开花的 $\mathrm{F}_{1}$ 代 (未发表数据)。报春苣苔属全部物种都具有相同的 染色体数目(Liu et al, 2012; Kang et al, 2014), 且多 数物种可以相互杂交并产生开花的 $\mathrm{F}_{1}$ 代, 预示着报 春苣苔属中多数物种间授粉后隔离可能普遍较弱。 牛耳朵和马坝报春苣苔具有较近的系统发育关系 (Kang et al, 2014), 因此两者的遗传分化可能还不 足以建立起强烈的授粉后隔离机制 (Luo et al, 2015)。牛耳朵和马坝报春苣苔的花期存在部分重叠, 但野外很少有自然杂交个体存在, 表明两者可以较 好地保持自身完整性, 由此推测授粉前隔离对阻止 牛耳朵和马坝报春苣苔杂交融合可能起到更为重要 的作用，比如，传粉者隔离(Xu et al, 2011)、传粉精 确性隔离(Huang \& Shi, 2013)及交配系统隔离(Brys et al, 2014, 2016)等都可能具有较强的作用, 但授粉 前的隔离机制需要在以后的研究中进一步证明。

从授粉后隔离强度来看, 马坝人遗址种群中的 牛耳朵和马坝报春苣苔发生杂交的可能性较大。自 然杂交可以产生新物种(Soltis \& Soltis, 2009), 但同 时也可能导致亲本物种的灭绝, 尤其是对狭域物种 
会产生更高的灭绝风险(Rhymer \& Simberloff, 1996;

Wolf et al, 2001)。马坝报春苣苔为极其狭域的特有 种(目前只有一个分布点), 在和牛耳朵发生基因流 时, 其很可能被遗传同化而导致灭绝, 因此在今后 的物种保护工作中应给予高度重视。

\section{致谢：感谢两位审稿专家提出的宝贵修改意见。}

\section{参考文献}

Ai B, Gao Y, Zhong XL, Tao JJ, Kang M, Huang HW (2015) Comparative transcriptome resources of eleven Primulina species, a group of 'stone plants' from a biodiversity hot spot. Molecular Ecology Resources, 15, 619-632.

Baack E, Melo MC, Rieseberg LH, Ortiz-Barrientos D (2015) The origins of reproductive isolation in plants. New Phytologist, 207, 968-984.

Brys R, Vanden Broeck A, Mergeay J, Jacquemyn H (2014) The contribution of mating system variation to reproductive isolation in two closely related Centaurium species (Gentianaceae) with a generalized flower morphology. Evolution, 68, 1281-1293.

Brys R, Cauwenberghe JV, Jacquemyn H (2016) The importance of autonomous selfing in preventing hybridization in three closely related plant species. Journal of Ecology, 104, 601-610.

Chung KF, Huang HY, Peng JI, Xu WB (2013) Primulina mabaensis (Gesneriaceae), a new species from a limestone cave of northern Guangdong, China. Phytotaxa, 92, 40-48.

Coyne JA, Orr HA (2004) Speciation. Sinauer Associates, Sunderland, MA.

Dafni A (1992) Pollination Biology. Oxford University Press, New York.

Gao Y, Ai B, Kong HH, Kang M, Huang HW (2015) Geographical pattern of isolation and diversification in karst habitat islands: a case study in the Primulina eburnea complex. Journal of Biogeography, 42, 2131-2144.

Huang SQ, Shi XQ (2013) Floral isolation in Pedicularis: how do congeners with shared pollinators minimize reproductive interference? New Phytologist, 199, 858-865.

Husband BC, Schemske DW, Burton TL, Goodwillie C (2002) Pollen competition as a unilateral reproductive barrier between sympatric diploid and tetraploid Chamerion angustifolium. Proceedings of the Royal Society B, 269, 2565-2571.

Kang M, Tao JJ, Wang J, Ren C, Qi QW, Xiang QY, Huang
HW (2014) Adaptive and nonadaptive genome size evolution in karst endemic flora of China. New Phytologist, 202, 1371-1381.

Kay KM (2006) Reproductive isolation between two closely related humming bird pollinated neotropical gingers. Evolution, 60, 538-552.

Klips RA (1999) Pollen competition as a reproductive isolation mechanism between two sympatric Hibiscus species (Malvaceae). American Journal of Botany, 86, 269-272.

Liu RR, Pan B, Zhou TJ, Liao JP (2012) Cytological studies on Primulina taxa (Gesneriaceae) from limestone karsts in Guangxi Province, China. Caryologia, 65, 295-303.

Luo ZL, Duan TT, Yuan S, Chen S, Bai XF, Zhang DX (2015) Reproductive isolation between sympatric sister species, Mussaenda kwangtungensis and M. pubescens var. alba. Journal of Integrative Plant Biology, 57, 859-870.

Martin NH, Willis JH (2007) Ecological divergence associated with mating system causes nearly complete reproductive isolation between sympatric Mimulus species. Evolution, 61, 68-82.

Möller M, Wei YG, Wen F, Clark JL, Weber A (2016) You win some you lose some: updated generic delineations and classification of Gesneriaceae-implications for the family in China. Guihaia, 36, 44-60.

Rhymer JM, Simberloff D (1996) Extinction by hybridization and introgression. Annual Review of Ecology, Evolution and Systematics, 27, 83-109.

Snow AA, Spira TP (1996) Pollen-tube competition and male fitness in Hibiscus moscheutos. Evolution, 50, 1866-1870.

Sobel JM, Chen GF (2014) Unification of methods for estimating the strength of reproductive isolation. Evolution, 68, $1511-1522$.

Soltis PS, Soltis DE (2009) The role of hybridization in plant speciation. Annual Review of Plant Biology, 60, 561-588.

Wang WT, Pan KY, Li ZY, Weitzman AL, Skog LE (1998) Gesneriaceae. In: Flora of China (eds Wu ZY, Raven PH), pp. 244-401. Science Press, Beijing \& Missouri Botanical Garden Press, St. Louis.

Wolf DE, Takebayashi N, Riesebrg LH (2001) Predicting the risk of extinction through hybridization. Conservation Biology, 15, 1039-1053.

Xu SQ, Schlüter PM, Scopece G, Breitkopf H, Gross K, Cozzolino S, Schiestl FP (2011) Floral isolation is the main reproductive barrier among closely related sexually deceptive orchids. Evolution, 65, 2606-2620.

(责任编委: 黄双全 责任编辑: 时意专) 